Article

\title{
The Turnera Style S-Locus Gene TsBAHD Possesses Brassinosteroid-Inactivating Activity When Expressed in Arabidopsis thaliana
}

\author{
Courtney M. Matzke ${ }^{1}$, Joel S. Shore ${ }^{2} \mathbb{D}$, Michael M. Neff ${ }^{3}$ and Andrew G. McCubbin ${ }^{1, *(\mathbb{C}}$ \\ 1 School of Biological Sciences, Washington State University, PO Box 644236, Pullman, WA 99164-4236, USA; \\ courtney.matzke@wsu.edu \\ 2 Department of Biology, York University, 4700 Keele Street, Toronto, ON M3J1P3, Canada; shore@yorku.ca \\ 3 Department of Crops and Soils, Washington State University, PO Box 644236, Pullman, WA 99164, USA; \\ mmneff@wsu.edu \\ * Correspondence: amccubbin@wsu.edu
}

Received: 21 October 2020; Accepted: 11 November 2020; Published: 13 November 2020

\begin{abstract}
Heterostyly distinct hermaphroditic floral morphs enforce outbreeding. Morphs differ structurally, promote cross-pollination, and physiologically block self-fertilization. In Turnera the self-incompatibility (S)-locus controlling heterostyly possesses three genes specific to short-styled morph genomes. Only one gene, TsBAHD, is expressed in pistils and this has been hypothesized to possess brassinosteroid (BR)-inactivating activity. We tested this hypothesis using heterologous expression in Arabidopsis thaliana as a bioassay, thereby assessing growth phenotype, and the impacts on the expression of endogenous genes involved in BR homeostasis and seedling photomorphogenesis. Transgenic $A$. thaliana expressing TsBAHD displayed phenotypes typical of BR-deficient mutants, with phenotype severity dependent on TsBAHD expression level. BAS1, which encodes an enzyme involved in BR inactivation, was downregulated in TsBAHD-expressing lines. CPD and DWF, which encode enzymes involved in BR biosynthesis, were upregulated. Hypocotyl growth of TsBAHD dwarfs responded to application of brassinolide in light and dark in a manner typical of plants over-expressing genes encoding BR-inactivating activity. These results provide empirical support for the hypothesis that TsBAHD possesses BR-inactivating activity. Further this suggests that style length in Turnera is controlled by the same mechanism (BR inactivation) as that reported for Primula, but using a different class of enzyme. This reveals interesting convergent evolution in a biochemical mechanism to regulate floral form in heterostyly.
\end{abstract}

Keywords: heterostyly; BAHD acyltransferase

\section{Introduction}

Most flowering plants bear flowers with male and female reproductive structures in close physical proximity. Logically this should lead to an inherent tendency to inbreed, but most angiosperm species have evolved mechanisms that promote outbreeding and/or prevent self-fertilization $[1,2]$. Such breeding systems help to maintain genetic diversity within species, a key factor for long term evolutionary success. In species that possess heterostyly, individual plants bear flowers of one of two (distyly) or three (tristyly) floral morphs, between which male and female organs are reciprocally positioned, promoting cross-pollination (Figure 1). These morphological differences are often combined with within-morph biochemical incompatibility, forming a breeding system that acts to prevent selfand intra-morph fertilization in addition to promoting out-crossing. The significance and widespread polyphyletic occurrence of heterostyly has garnered the attentions of many researchers seeking to unravel the evolutionary and genetic mechanisms of the polymorphism. 


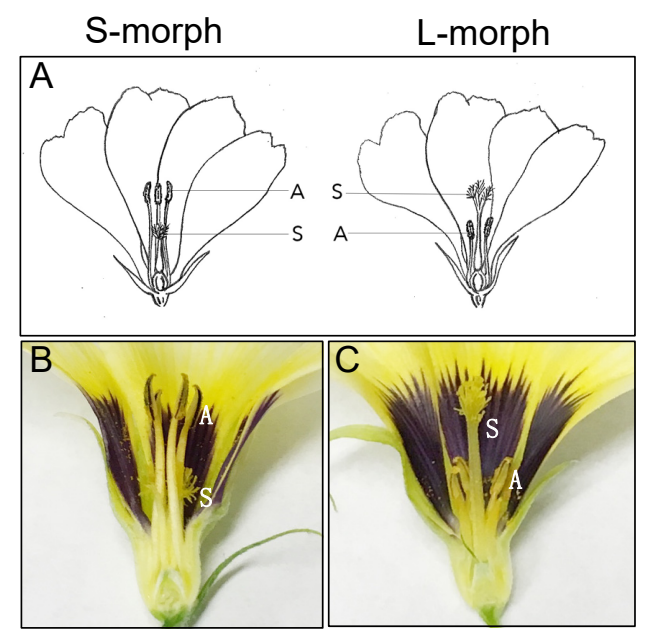

Figure 1. Phenotypes of short (S-morph) and long (L-morph) style morphs. (A) Diagram showing reciprocal arrangement of stigma and style (S) and anthers and stamens (A). (B,C) Longitudinal section of a mature flower showing the short morph and long morph of Turnera subulata.

Darwin was intrigued by this phenomenon, and after extensive studies in Primula was the first to conclude that the significance of the floral forms lies in contributing to outcrossing [3]. Being a trait readily scored by eye, heterostyly was a popular model in the early efforts to demonstrate single trait Mendelian inheritance [1]. Later the discovery of rare natural homostyle individuals, which bear flowers in which stamen and stigma are at the same level, generated further interest. Subsequent analyses led to the proposition that heterostyly is controlled by a supergene locus, the "S-locus," comprised of several tightly linked genes with recombination between alleles occurring only very rarely, but leading to homostyly [4]. Such interpretations inferred the short styled (S)-morph to be heterozygous for the $S$-locus, Ss, and the long styled (L)-morph homozygous recessive, ss $[5,6]$. As hemizygous (see below) supergene loci involved in controlling mating type, S-loci controlling heterostyly are far from unique; indeed, they share functional and physical commonalities with sex chromosomes (the $S$-locus-bearing chromosome is akin to the $\mathrm{Y}$ chromosome), albeit that in heterostyly mating types retain hermaphroditism. The genes that control these breeding barriers are of interest as potential tools with which to engineer new or improved barriers in and between agricultural species and their relatives.

In recent years, genes within the $S$-locus that control distyly have been identified in several unrelated genera, including Primula, Turnera, and Fagopyrum (see [7] for review). Surprisingly, though these genera appear to have independently evolved heterostyly, genetically their $S$-loci all appear to function in a manner contrary to the historical dogma. Rather than there being dominant and recessive $S$-alleles as previously accepted, the genes are in fact hemizygous, being present in the S-morph, but lacking allelic counterparts in the L-morph [8-11]. These S-genes, their roles in heterostyly, and their modes of action are focal points of current research.

In Primula, five genes have been identified within the S-locus: CYP734A50 (a cytochrome p450), GLOBOSA2 (GLO2, a MADS box transcription factor), PUM (a Pumilio-like RNA-binding protein), CCM (a cyclin-like F box gene), and KFB (a Kelch repeat $\mathrm{F}$ box protein) [10,12-15]. CYP734A50 is a member of the P450 CYP734A cytochrome family expressed in pistils [13]. The closest Arabidopsis thaliana homolog of CYP734A50 is PHYB ACTIVATION-TAGGED SUPRESSOR1 (BAS1), a gene that encodes an enzyme with BR degrading activity $[13,16]$. This observation led to an elegant set of experiments that demonstrated that Primula CYP734A50 controls pistil length in the S-morph by reducing cell expansion by degrading BRs [13]. GLOBOSA2 (GLO2) is a MADS-box transcription factor expressed specifically in S-morph stamens $[10,12,15]$, and was recently shown to control (elevate) anther height by promoting cell expansion in the corolla tube below the point of anther filament insertion [14]. The potential functions of the other three Primula S-genes are as yet unknown. In Fagopyrum, style length 
is regulated by $S$-locus early flowering 3 (S-ELF3), a homolog of $A$. thaliana ELF3, a nuclear protein that interacts with phytochrome $B$ to control plant development and flowering $[8,9]$.

The Turnera S-locus possesses only three genes. Based on homology to known gene families, they have been named TsSPH1 (homologous to Papaver rhoeas stigma incompatibility S-protein), Ts YUC6 (homologous to the YUCCA gene family of flavin-dependent monooxygenases), and TsBAHD (homologous to the BAHD acyltransferase family) [11]. TsSPH1 is expressed in filaments and anthers, and may be involved in controlling filament length [11]. TsYUC6, is expressed in anthers, potentially involved in auxin synthesis, and likely to control pollen incompatibility mating type $[11,17,18]$. The third gene, TsBAHD, has conserved motifs found in BAHD acyltransferases and is the only $S$-gene expressed in pistils, necessitating that it controls all female characteristics, including style length.

The closest characterized $A$. thaliana homologs of TsBAHD include genes reported to acetylate and inactivate BRs [19]. This leads us to hypothesize that TsBAHD causes short styles in Turnera by acetylating and inactivating BRs, employing the same mechanism as that found in Primula but effected by a different class of BR-inactivating enzyme [11,13]. Support for this hypothesis has been found in the form of patterns of BR regulated gene expression in transcriptome analyses, where depletion of BR regulated genes was found in S-morph relative to L-morph pistils [20]. However, an empirical test of this hypothesized activity is lacking, but necessary. The BAHD family is a large gene family (with 64 members in A. thaliana alone) that consists of acyltransferases that catalyze transfer of acyl-groups from CoA thioester compounds to several different types of plant metabolites [21]. BAHD is an acronym composed of the first four active enzymes that were classified biochemically, BEAT (benzyl alcohol $O$-acetyltransferase from Clarkia breweri), AHCT (anthocyanin O-hydroxycinnamoyltransferase from Gentiana triflora), HCBT (N-hydroxycinnamoyl/benzoyltransferase from Dianthus caryophyllus), and DAT (deacetylvindoline 4-O-acetyltransferase from Catharanthus roseus) [22]. The majority of BAHD genes have not been characterized, and though it is reasonable to assume based on conserved sequence motifs, that TsBAHD is in the BAHD protein family, inferring biochemical function by sequence homology alone has proven difficult in this family [23]. Amino acid alignments used to create phylogenetic trees separate BAHD family members into five different clades predicted to share either substrate preference or conditions for activity [23-25]. Even though these analyses may place a gene within a certain clade, characteristics such as substrate preference and function are not always similar [23]. Hence additional work was required to further biochemically characterize TsBAHD.

BRs play several roles in plant development, including promoting cell elongation [26]. BRs are found at very low concentrations in plant tissues and cannot be transported extracellularly [27], their homeostasis is tightly regulated by negative feedback loops and multiple mechanisms of inactivation [28]. A. thaliana plants mutated to prevent synthesis of the bioactive BR brassinolide (BL) exhibit severe dwarf phenotypes typically with shortened stems and petioles, shortened, epinastic, dark green leaves, delayed senescence, and infertility (for review see [26]). Importantly, these phenotypes can be rescued by application of exogenous BL [29-31].

Several BR biosynthetic genes have been identified, including DE-ETIOLATED2 (DET2) [29], DWARF4 (DWF4) [28], and CONSTITUTIVE PHOTOMORPHGENESIS AND DWARFISM (CPD) [30], and these are upregulated in A. thaliana plants with low levels of BR [32]. To maintain BR homeostasis, catabolic enzymes are also dynamically expressed and are active along several parts of the BR pathway to degrade or inactivate BR. Increased expression of these catabolic enzymes leads to reduced BR and characteristics typical of BR-deficient dwarfs. For example, over-expression of BAS1, which encodes an enzyme that inactivates BRs by hydroxylation, results in shortened hypocotyls [16,33]. Members of the BAHD acyltransferase family, including BRASSINOSTEROID INACTIVATOR1 (BIA1) and BIA2, have been also been assessed using over-expression bioassays in $A$. thaliana, and have been reported to possess BR inactivation activity effected by acyl conjugation of BRs [19,34].

In this study, we investigated whether TsBAHD encodes, as hypothesized, a BR degrading acyltransferase [11], by employing a bioassay in which TsBAHD was over-expressed in A. thaliana. 
We show that TsBAHD caused dwarf phenotypes consistent with BR-deficiency. These dwarfs exhibited upregulation of genes encoding classic BR biosynthesis enzymes, DWF4 and $C P D$, and downregulation of a gene encoding the BR degrading enzyme, BAS1. Exogenous BL application led to increased hypocotyl growth in $35 S:: T s B A H D$ dwarfs similar to that seen in wild type plants when grown in the light. In contrast, very little growth occurred in BL treated 35S::TsBAHD lines when grown in the dark. These data provide empirical evidence consistent with TsBAHD possessing BR-inactivating enzyme activity, and further suggest this activity involves acylation of BL rather than targeting earlier intermediates in the BR synthesis pathway.

\section{Results}

\subsection{Expression of TsBAHD in A. Thaliana Induces Dwarfism}

A. thaliana plants were transformed with 35S::TsBAHD by floral dip [35], using Agrobacterium strain GV 31010 [36]. Transformants were initially identified by kanamycin selection and the presence of the transgene confirmed by PCR (Figure 2). Independent lines were selected, assessed to possess single locus insertions based on segregation of kanamycin resistance, and three independent homozygous lines (35S::TsBAHD lines 25, 54, and 63) were generated. Though all progeny for all three lines displayed dwarf phenotypes, within all lines the severity of dwarfism varied between individuals. To facilitate further investigation, plants were selected representing severe (S), intermediate (I), or weak (W) dwarf phenotypes (Figure 3A). Severe dwarfs were extremely reduced in stature with very small, epinastic, dark green leaves, and reduced inflorescence that set very little seed on self-fertilization. Intermediate dwarfs were similar to but somewhat larger than $S$ dwarfs, and had longer flower stalks and higher self-fertility. Weak dwarfs had larger, lighter green leaves and longer stems, but were still substantially reduced in size relative to wild type. Fertility in the weak dwarfs was also closer to wild type, although the flower stalks were still much shorter than those of wild-type plants (Figure 3A). These phenotypes are consistent with those reported for BR-deficient mutants, including DET2, DWF4, and BAS1 [16,28-30]. We reasoned that the variations in phenotype might relate to expression level of the transgene caused by variable transgene silencing. This hypothesis was tested using qPCR to assess TsBAHD expression in S, I, and W dwarfs of all three lines. This analysis showed that the severity of dwarfism correlated well with TsBAHD expression in the transgenic lines. Expression was consistently lowest in $\mathrm{W}$ dwarfs and higher in I and $\mathrm{S}$ dwarfs, with $\mathrm{S}$ dwarfs exhibiting the highest expression levels in 35S::TsBAHD lines 54 and 63, though not significantly different from I dwarfs in line 25 (Figure 3B). These results are broadly consistent with TsBAHD expression inducing the observed dwarfism, leading us to investigate whether this dwarfism was mediated by BR degradation.

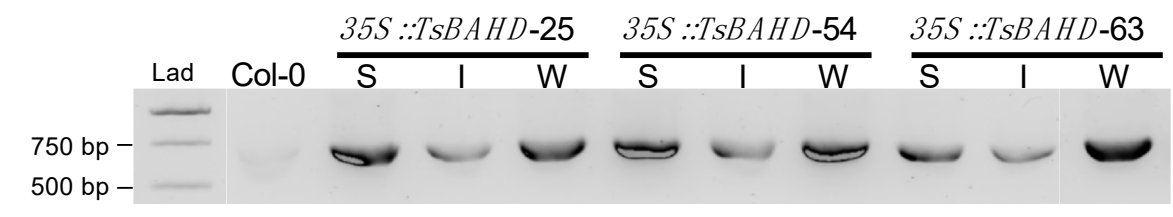

Figure 2. Confirmation of insert in transgenic lines in $A$. thaliana. Three independent lines of the TsBAHD overexpression construct. Each 35S::TsBAHD line has been confirmed in severe (S), intermediate (I), and weak (W) dwarf phenotypes, represented by the three bands under each 35S::TsBAHD line in corresponding order. Expected fragment size is $683 \mathrm{bp}$. Each lane contained $5 \mu \mathrm{L}$ of PCR product and $2 \mu \mathrm{L}$ of loading dye. LAD was $5 \mu \mathrm{L}$ of a $1 \mathrm{~kb}$ DNA ladder.

\subsection{Assessment of Expression of BR Biosynthesis and Inactivating Genes}

BR homeostasis is maintained by feedback regulation, mediated by variable expression of a number of genes [26]. Relative to wild-type plants, BR-deficient dwarfs typically display up-regulation of genes involved in BR biosynthesis and down-regulation of those involved in BR inactivation [32,37,38]. To assess whether the dwarf phenotypes were associated with altered BR signaling, expressions of 
several well characterized genes related to BR biosynthesis and inactivation were measured (Figure 4). Two canonical genes that encode enzymes involved in BR biosynthesis, DWF4 and CPD, showed elevated expression in all dwarf phenotypes relative to wild-type plants (Figure 4A,B). S dwarfs showed the largest increase in CPD expression, exhibiting statistically significant 2-3 fold increases in the three independent lines when compared to the wild type ( $p$-values $<0.01$ ). I dwarfs exhibited significant $1-2$ fold increases in two lines ( $p$-values 0.001 and 0.002 ), and an increase in the third line that was not statistically significant. W dwarfs also showed significant increases compared to wild type in two lines ( $p$-values 0.002 and 0.04). Expression of DWF4 relative to the wild type showed a 2-3 fold increase in S dwarfs ( $p$-values 0.001 and 0.04). I and W dwarfs showed smaller, less statistically significant increases ( $p$-value 0.01). BAS1, which encodes a BR-inactivating enzyme, showed lowered expression relative to wild type in all three dwarf phenotypes (Figure 4C). I and W dwarfs showed largest and the most significant decreases with almost 3-fold reductions ( $p$-values 0.02-0.04). S dwarfs showed an about 2 fold decrease with a significant $p$-value in one line (0.04). These patterns of gene regulation in the $35 S:: T s B A H D$ lines are consistent with those that would be expected if altered BR levels underpin the dwarf phenotypes. We next sought to determine if application of exogenous BR could rescue 35S:TsBAHD induced dwarfism.

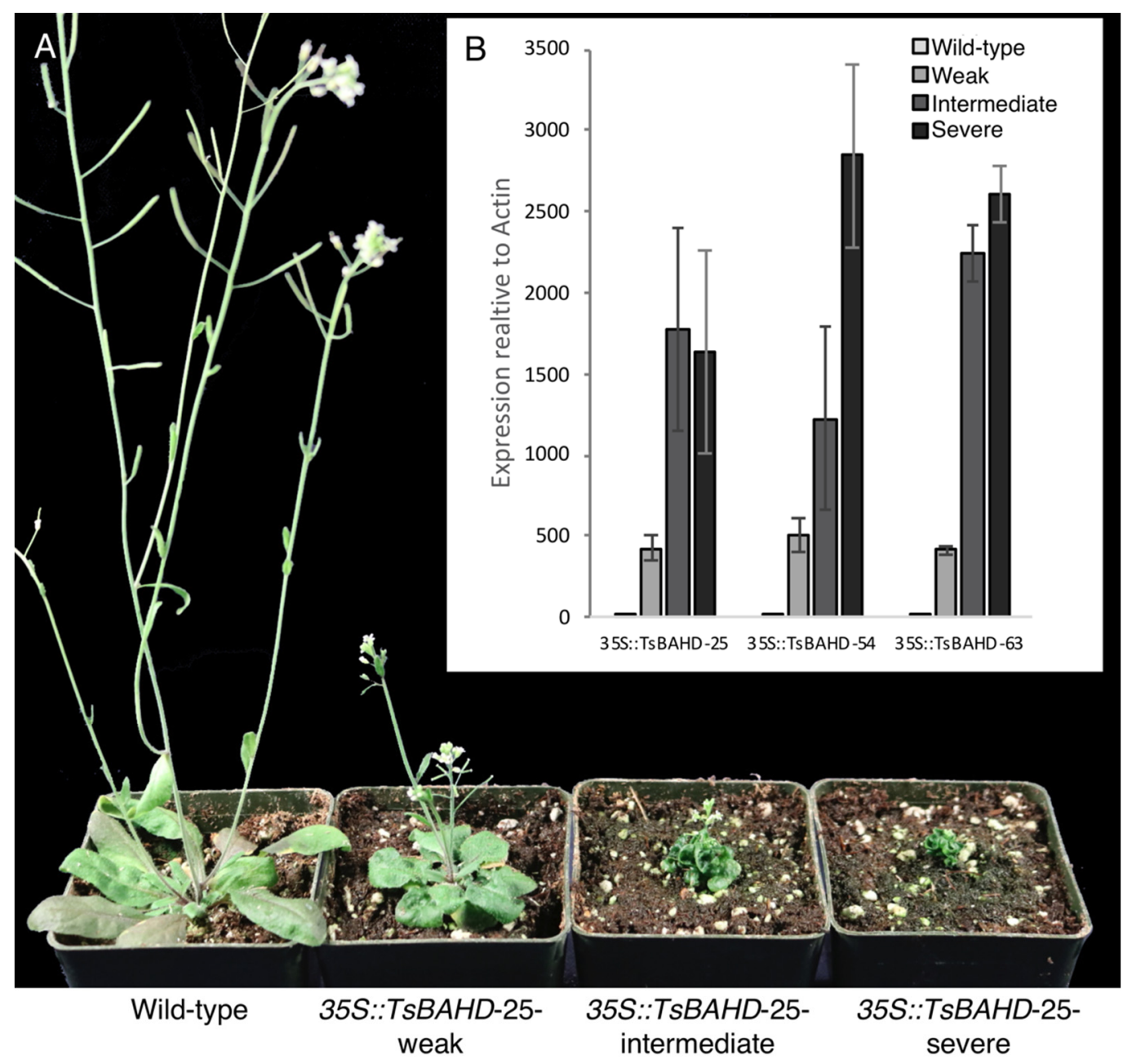

Figure 3. Phenotypes and expression of $35 S:: T s B A H D-25$ in A. thaliana normalized to the actin 8 (At1g4920) housekeeping gene. (A) From left to right: six week old plants of wild type (Col-0) compared to three 35S::TsBAHD (line 25) transformants showing weak, intermediate, and most severe dwarf phenotypes. (B) Expression of 35S::TsBAHD lines 25, 54, and 63 in S, I, and W dwarfs compared to the wild type. Wild-type samples were included as a negative control. Errors bars represent standard error. 


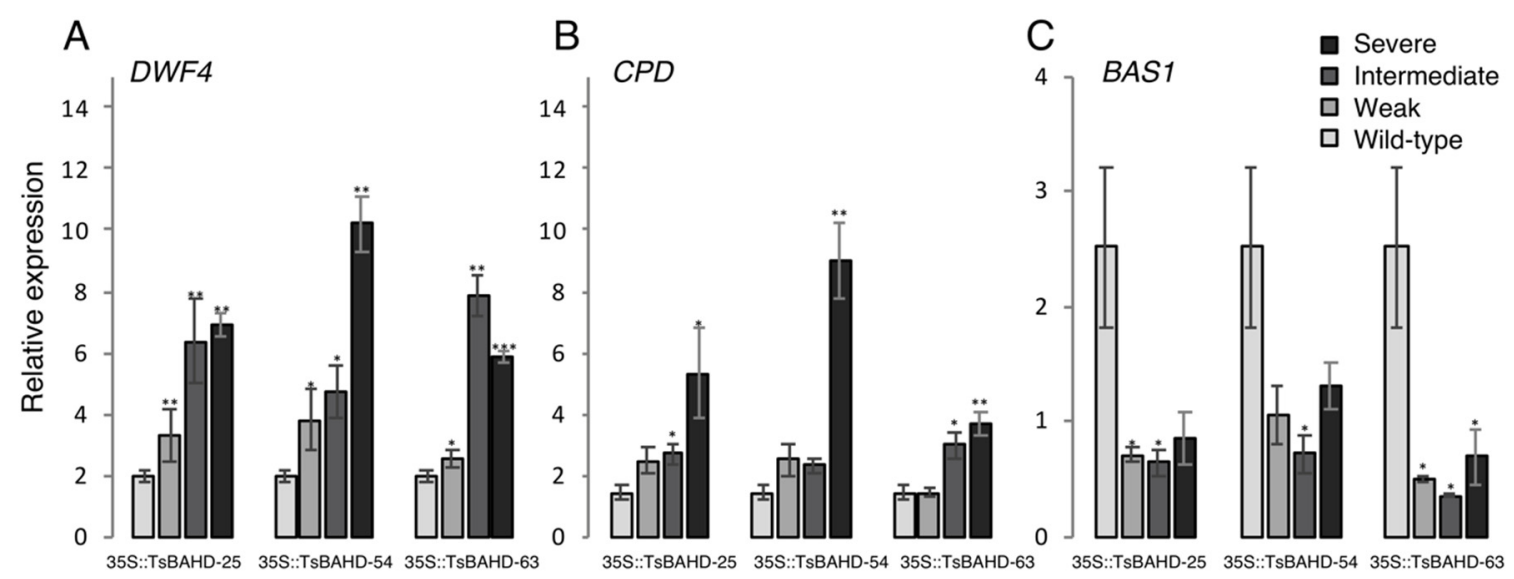

Figure 4. Relative expression of BR biosynthesis and inactivating genes in 35S::TsBAHD normalized to an actin housekeeping gene. Expressions of DWF4 (A), CPD (B), and BAS1 (C) in six week old 35S::TsBAHD lines 24, 54, and 63. All 35S::TsBAHD transformants showing S, I, and W phenotypes compared to the Col-0 wild type. Each qRT-PCR value is the mean of three replicates. Errors bars represent standard error. $p$-values comparing 35S::TsBAHD lines to the wild type were calculated using Student's $t$-test comparing each line to the wild-type expression ${ }^{*} p<0.05,{ }^{* *} p<0.01,{ }^{* * *} p<0.001$.

\subsection{Response of TsBAHD Expressing Hypocotyls to Exogenous BR in Light and Dark}

To determine if dwarfism in 35S::TsBAHD transgenic lines could be rescued by addition of BRs, dwarfs were grown in increasing concentrations of BL under different light conditions and hypocotyl growth was measured. If the TsBAHD protein is involved in BR inactivation, in 35S::TsBAHD hypocotyls are expected to be shorter than those of the wild type when grown in the light, and exhibit a de-etiolated hypocotyl phenotype when grown in the dark. In the light in the absence of BL, transgenic lines exhibited significantly shorter hypocotyl lengths (mean $=0.93 \mathrm{~mm}$; S.E. $=0.03$ ) than the wild type $($ mean $=1.6 \mathrm{~mm}$, S.E. $=0.03$ ) (Figure 5A,B). At $10 \mathrm{nM} \mathrm{BL}$, wild type and dwarf hypocotyls increased in length, and by $100 \mathrm{nM}$, the lengths of the wild type (mean $=3.54 \mathrm{~mm}$, S.E. $=0.07$ ) and all three lines of $35 S:: T s B A H D$ (mean, $3.04 \mathrm{~mm}$; S.E. $=0.52$ ) had significantly longer hypocotyls relative to their lengths at $0 \mathrm{nM}$. Two of the 35S::TsBAHD lines increased in hypocotyl length in response to increasing BL concentration at approximately the same rate as the wild type but remained shorter. One line, however, $35 S:: T s B A H D-54$, showed a greater response to BL and reached a similar length (mean $=2.2 \mathrm{~mm}$ ) to the wild type (mean, $2.1 \mathrm{~mm}$ ) by $10 \mathrm{nM}$ BL. Analysis by two-way ANOVA revealed marked phenotype effects (F2,45 $=25.5, p$-value $\leq 0.001)$, no strain effects $(F 2,45=2.64, p$-value $=0.08)$, and a marginally significant interaction $(\mathrm{F} 4,45=2.74, p$-value $=0.04)$.

In contrast, when grown in the dark in the absence of BL, 35S::TsBAHD seedlings had drastically shorter hypocotyls (average $2.6 \mathrm{~mm}$ ) than the etiolated wild type plants grown on the same plate $(9.1 \mathrm{~mm})$. As the concentration of exogenous BL applied increased, wild type hypocotyl length severely decreased (from $9.05 \mathrm{~mm}$ S.E. $=0.13$, to $5.5 \mathrm{~mm} \mathrm{S.E.}=0.08$ ). On average, the 35S::TsBAHD lines showed a small gradual increase if any change was observed (Figure 5C,D). Between 10 and $100 \mathrm{nM}$, two of the $35 S:: T s B A H D$ lines remained the same or showed a minor decrease. The third line 35S::TsBAHD-54 showed a small increase in hypocotyl length (from 3.8 to $5.2 \mathrm{~mm}$ ). 
A

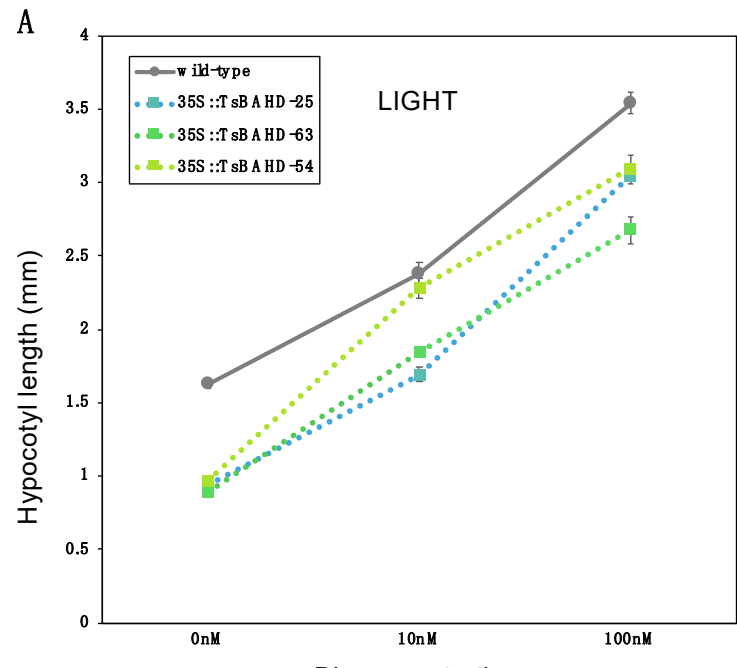

C

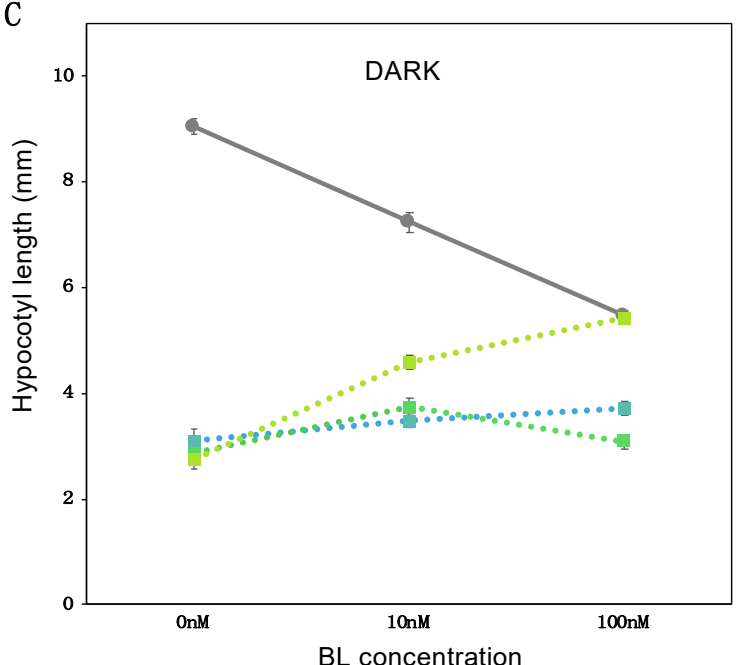

B

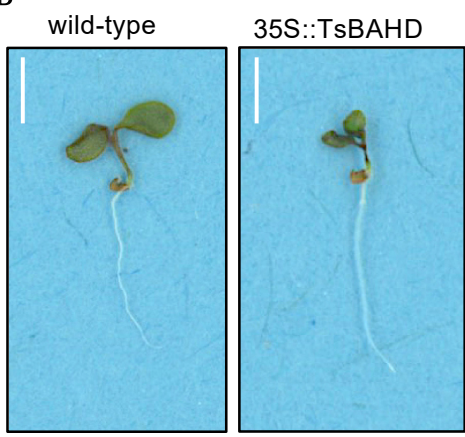

D

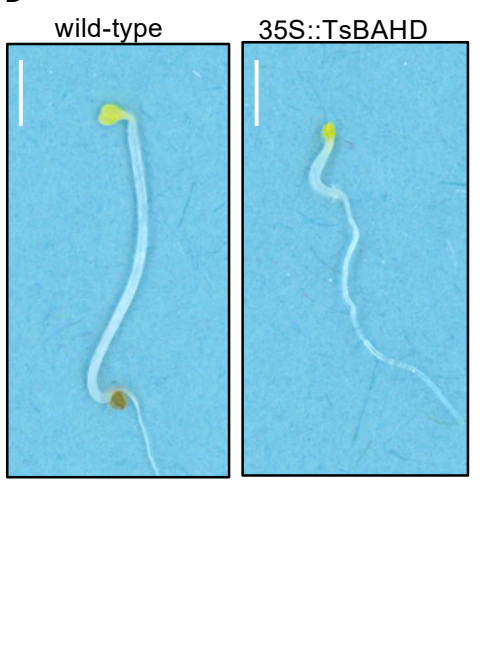

Figure 5. Hypocotyl response to different concentrations of brassinolide (BL) in light $(\mathbf{A}, \mathbf{B})$ and dark $(\mathbf{C}, \mathbf{D})$. Seedlings pictured are representatives of wild type and 35S::TsBAHD lines from plates with $0 \mathrm{nM}$ BL. Hypocotyls of 4 day old seedlings were grown on plates at $25^{\circ} \mathrm{C}$ in continuous light at an intensity of $80 \mu \mathrm{E}$ and in complete darkness. Plates contained half strength Linsmaier and Skoog modified basal medium, $0.6 \%$ Gellan, and 1.5\% sucrose. BL concentrations were 0, 10, and $100 \mathrm{nM}$. Green dotted lines represent two replicates of three independent lines of $35 S:: T s B A H D$ and solid gray line represents the wild type. Errors bars represent standard error. Scale bars $=2 \mathrm{~mm}$.

\section{Discussion}

In this study, the mechanism controlling heterostyly in Turnera was investigated. TsBAHD was recently identified as the G (gynoecium) component of the S-locus in Turnera that determines this trait [11]. The S-locus in Turnera is hemizygous, being present as a single copy in the short style morph, and absent from the long-styled morph, as is also the case for the S-locus of Primula [11]. In Primula the $S$-locus gene controlling style length is CYP734A50, a BR degrading enzyme with homology to BAS1, which degrades BRs in $A$. thaliana. TsBAHD in contrast shares homology with BAHD acyltransferases, as some members of this gene family acetylate and inactivate BRs. We previously hypothesized that TsBAHD may also be capable of inactivating BRs [11]. If this is the case it would suggest convergent evolution between the S-loci of Turnera and Primula, such that different BR-inactivating different genes have been recruited to the $S$-locus to cause shortened style length. To investigate this possibility and the biochemical function of $T s B A H D$, the gene was expressed in $A$. thaliana. 
A. thaliana plants expressing TsBAHD displayed dwarf phenotypes typical of BR-deficient mutants including small, epinastic, dark green leaves, shortened stems, and self-infertility. The severity of dwarfism was variable but correlated with the expression level of TsBAHD, consistent with the transgene being responsible for the phenotype. Transgene suppression is a likely cause of the phenotype variability. Due to the very low levels of BRs present in plants and the lack of long-distance transport, the homeostasis of precursors and intermediates in the BR pathway is tightly regulated [39]. When BR levels approach either low or high levels, the expression of genes involved in the regulatory pathway changes, leading to either synthesis or inactivation of BRs. To determine if expression of TsBAHD had perturbed expression of genes involved in BR homeostasis, we assessed the expression of two genes involved in BR biosynthesis (DWF4 and CPD), and one in BR inactivation (BAS1) in the transgenic plants relative to wild type plants. The expression of DWF4 and $C P D$ increased with increased transgene expression, whereas BAS1 decreased, consistent with TsBAHD expression, leading to reduced BR levels in the transgenic lines. These results are consistent with a negative feedback response resulting from low BRs concentrations within plants expressing TsBAHD.

Studying the effect of light, in combination with BR treatment on hypocotyl growth, was also informative. BRs are important in photomorphogenesis, and so have major impacts on growth and development in a light dependent manner [29,30,40]. When grown in the light, the hypocotyl length of $35 S:: T s B A H D$ lines was significantly reduced compared to wild type, which is a characteristic of BR mutants. When germinated in the dark 35S::TsBAHD seedlings showed a severely reduced etiolation response or lacked one entirely. The results of this study are consistent with previous work on BR-deficient dwarfs grown in light or complete darkness [16,19,40,41]. Additional information as to which form of BR may be the substrate of this enzyme was gleaned by assessing the ability of BL to rescue TsBAHD induced dwarfism. In the light, as BL was added in increasing concentrations up to $100 \mathrm{nM}, 35 S:: T s B A H D$ hypocotyls increased in length at approximately the same rate and proportion as wild type, showing that exogenously applied BL was not able to fully rescue the phenotype. Conversely, when grown in the dark with BL, a subtle decrease in hypocotyl length or lack of effect was observed for the 35S::TsBAHD lines. Again these results mirror those previously reported in several BL dose response experiments in which BR degrading genes were overexpressed [16,34,41,42]. The drastic decrease observed in hypocotyl length of wild type seedlings when grown in increasing amounts of BL in the dark may be due to toxicity of the excess amount of BL suddenly present. As BR is usually present in small quantities within plant tissues, overabundance may halt and decrease development as the plant is unable to process the excess. Alternatively, it may be that in the dark, since BL is the endpoint of the pathway, exogenous BL application is not sufficient to signal activation of the degradation pathway [37]. The results provide clues as to which intermediate in the BR pathway TsBAHD may be acting upon. If the substrate for TsBAHD is later in the pathway, such as the end product BL, exogenously applied BL would be immediately inactivated, and so have little effect on hypocotyl length. If instead the substrate for TsBAHD is a precursor or intermediate(s) earlier on in the pathway, then the expected result would be reestablishment of active BL and other products further downstream. The lack of ability of BL to rescue the phenotypes observed in this study suggests that the preferred substrate for the TsBAHD enzyme is an end product of the BR biosynthesis pathway, possibly BL itself.

Together, the results presented in this study are consistent with overexpression of TsBAHD leading to dwarf phenotypes resulting from reduced BR levels, and provide substantial empirical support for the hypothesis that TsBAHD encodes a BR-inactivating enzyme. As TsBAHD is the only S-locus gene expressed in pistils in Turnera subulate; this suggests that style length in this species is controlled by the same mechanism (BR inactivation) as that reported in Primula [13], albeit using different genes encoding distinct enzyme activities. Hence a novel example of convergent evolution in a biochemical mechanism to regulate floral form in heterostyly has been revealed. As this mechanism appears to have evolved twice to generate a breeding barrier in distinct species, it is tempting to speculate that it 
may be a pathway through which flower morphology and/or breeding barriers might be engineered in other plant species.

\section{Materials and Methods}

\subsection{Plasmid Construction and Generation of Transgenic Lines}

The polymerase chain reaction (PCR) was used to amplify the TsBAHD coding sequence (GenBank: MK922466.1) from a bacterial artificial chromosome clone, BAC-A24 (11) using Accuzyme A $^{\mathrm{TM}}$ proofreading Taq DNA polymerase (Bioline, USA). Gene-specific primers created for amplification were (5'-TTAAGATATGGAAGTTGAGAT- ${ }^{\prime}$ and $5^{\prime}$-CAAAAGCATGATTCTG- ${ }^{\prime}$ ) at $58{ }^{\circ} \mathrm{C}$ annealing temperature. The cloned gene was ligated into pGEM-T ${ }^{\circledR}-\mathrm{T}$ Easy vector (Promega, USA). DNA was purified using the ZR Plasmid Miniprep-Classic and Zymoclean ${ }^{\mathrm{TM}}$ Gel DNA Recovery Kit according to the manufacturers' instructions (ZymoResearch, USA) and sequenced. BamH1 and Kpn1 restriction sites were added using primers (5'-GGTACCTTAAGATATGGAAGTTGAGAT-3' and 5'-GGATCCCAAAAGCATGATTCTG-3') to facilitate cloning behind the cauliflower mosaic virus (CaMV) 35S promoter in the binary vector pCHF3 [16]. After verifying the insert by Sanger sequencing, transformation constructs were then transformed into Agrobacterium strain GV3101 and the floral dip method used to transform the A. thaliana ecotype Col-0 [35].

\subsection{Plant Growth Conditions and Transformation Screening}

In all experiments, $A$. thaliana seeds were surface sterilized by shaking for 15 min at room temperature in a solution of $70 \%$ ethanol, $0.05 \%$ Triton $X 100$. This was repeated with $95 \%$ ethanol, $0.05 \%$ Triton X 100 followed by a rinse with 95\% ethanol. Seedlings were grown on half strength Linsmaier and Skoog modified basal medium, 0.8\% Phytoblend (Caisson Laboratories, Smithfield, UT, USA), and $1.5 \%$ sucrose. Plates were placed in a cold, dark environment $\left(4{ }^{\circ} \mathrm{C}\right)$ for 3 days to promote even germination. Growth chamber conditions for all seedlings (unless otherwise noted) were $100 \mu \mathrm{mol} \mathrm{m} \mathrm{m}^{-2} \mathrm{~s}^{-1}$ of light for $16 \mathrm{~h}$ and $\left(20^{\circ} \mathrm{C}\right) / 8 \mathrm{~h}$ dark $\left(16^{\circ} \mathrm{C}\right)$. Transformants were identified by survival on the antibiotic selection plates $(30 \mu \mathrm{g} / \mathrm{mL}$ kanamycin). After 7 days, seedlings were transferred to individual pots containing SunGrow professional soil mix \#1 (Sun Gro Horticulture, Agawam, MA, USA) and allowed to set seeds, which were harvested when fully desiccated. In all experiments wild-type plants were untransformed Columbia-0 (Col-0). Direct PCR amplification was done with MyTaq ${ }^{\mathrm{TM}}$ Plant-PCR 2X Mix (Bioline, Memphis, TN, USA), a small (0.7 mm) fresh leaf tissue disc, and gene-specific primers to confirm the presence of the T-DNA. Sequences of all primers used are listed in Table S1. PCR products were run on a $1.5 \%$ gel at $150 \mathrm{~V}$ stained with SYBRSafe ${ }^{\mathrm{TM}}$ (ThermoFisher, Waltham, MD, USA). $\mathrm{T}_{2}$ seeds were grown on selection plates and screened for single locus insertion by calculating chi-square values to verify a ratio of 3:1 resistant: sensitive plants. The single locus insertion lines were then grown for seed and plated again. By the $\mathrm{T}_{4}$ generation all plants in all three lines used for further experiments were kanamycin resistant and assumed to be homozygous. All $\mathrm{T}_{4}$ plants were grown in growth chambers and analyzed by comparison with the Col-0 wild type plants.

\subsection{RNA Extraction, Reverse Transcription, and RT-qPCR Analyses}

Fresh whole plant tissue from 6-week-old A. thaliana plants was flash frozen in liquid nitrogen and total RNA isolated using the RNeasy ${ }^{\circledR}$ Plant MiniKit (Qiagen, Germantown, MD, USA). RNA samples were treated with DNase I (ZymoResearch, Irvine, CA, USA) to remove genomic contamination, followed by a clean-up step performed using the RNeasy ${ }^{\circledR}$ Plant MiniKit according to manufacturer's recommendations. RNA quality and quantity were determined using a NanoDrop ND-2000c spectrophotometer (ThermoFisher, USA). cDNA was synthesized with 100 ng of RNA using a ProtoScript ${ }^{\circledR}$ First Strand cDNA Synthesis Kit (New England Biolabs, Ipswich, MA, USA). Real time quantitative PCR (q-PCR) was performed using the C1000 Touch ${ }^{\mathrm{TM}}$ ThermoCycler with 
the SsoAdvanced ${ }^{\mathrm{TM}}$ Universal SYBR ${ }^{\circledR}$ Green Supermix following the manufacturer's instructions (BioRad, Hercules, CA, USA). Reactions consisted of $10 \mu \mathrm{L}$ of Sso Advanced ${ }^{\mathrm{TM}}$ Universal SYBR Green Supermix, $4 \mu \mathrm{L}$ of $10 \mu \mathrm{M}$ forward and reverse primers, $100 \mathrm{ng}$ of cDNA template, and water to $20 \mu \mathrm{L}$. PCR cycling parameters included an initial denaturation for $30 \mathrm{~s}$ at $95{ }^{\circ} \mathrm{C}$ followed by 35 cycles of $95^{\circ} \mathrm{C}$ denaturation, $60^{\circ} \mathrm{C}$ annealing, and $72{ }^{\circ} \mathrm{C}$ extension. Final extension was performed at $65^{\circ} \mathrm{C}$ for $5 \mathrm{~min}$. All reactions were analyzed with a melt curve to determine if any genomic DNA contamination was present. All samples were normalized to the expression of A. thaliana Actin 8 (At1g4920) as an internal control (Nelson and Steber, 2017). Three independent transformants were used as biological replicates for each sample. Expression levels of TsBAHD, DWF4, CPD, and BAS1 were assessed using primer pairs specific to each gene (listed in supplemental Table S1). Gene expression relative to the wild type was calculated using the $2^{-\Delta \Delta C T}$ method [43] using actin 8 as a control housekeeping gene. $p$-values comparing 35S::TsBAHD lines to wild type were calculated using Student's t-test. Values were assigned as follows: ${ }^{*} p<0.05,{ }^{* *} p<0.01,{ }^{* * *} p<0.001$. Standard error was calculated for all samples in each group.

\subsection{BL Dose Response Growth and Hypocotyl Measurements}

A. thaliana seeds were surface sterilized (as above) and plated with half strength Linsmaier and Skoog modified basal medium, $0.6 \%$ Gellan, and $1.5 \%$ sucrose [44]. Plates were supplemented with BL at concentrations of $0 \mathrm{nM}, 10 \mathrm{nM}$, or $100 \mathrm{nM}$ as described in Turk et al. [33]. After incubation in complete darkness for 4 days at $4{ }^{\circ} \mathrm{C}$, germination was then induced by exposure to red-light at $70 \mathrm{mmol} \mathrm{m}^{-2} \mathrm{~s}^{-1}$ for $2 \mathrm{~h}$ at $25^{\circ} \mathrm{C}$. All plates were then transferred to the same growth chamber in either light or dark conditions for 4 days at $25^{\circ} \mathrm{C}$. White light was continuously provided (to maximize the de-etiolation response) to light grown seedlings at $80 \mu \mathrm{E}$. Dark treated plates were exposed to the identical conditions, but light exposure was prevented by wrapping in two layers of aluminum foil. Growth and hypocotyl measurements were performed as described by Sandhu et al. [45]. Briefly, individual seedlings were removed from plates and placed on acetate sheets where hypocotyl lengths were scanned using a flat-bed scanner at a resolution of $1200 \mathrm{dpi}$. Hypocotyl lengths were determined from the scanned images using ImageJ [46]. Hypocotyls from each group were measured, averaged, and compared using the Student's t-test. Three independent homozygous lines were grown in two separate replicates at different times in the same growth chamber and conditions. $p$-values were calculated using Student's t-test and standard error calculated for all samples in each group.

Supplementary Materials: The following are available online at http://www.mdpi.com/2223-7747/9/11/1566/s1, Table S1: PCR primers.

Author Contributions: Conceptualization, A.G.M., J.S.S., and M.M.N., methodology, C.M.M., validation, C.M.M. and M.M.N., formal analysis, C.M.M. and J.S.S., investigation, C.M.M., resources, J.S.S., writing-original draft preparation, C.M.M., writing-review and editing, A.G.M., supervision, A.G.M., J.S.S., and M.M.N., project administration, A.G.M., funding acquisition, J.S.S. All authors have read and agreed to the published version of the manuscript.

Funding: This work was supported by NSF MCB170034 (A.G.M.) and an NSERC grant (J.S.S.).

Acknowledgments: The authors would like to thank Anna Hulbert and Amber Hauvermale for technical assistance with $A$. thaliana transformation and qPCR respectively.

Conflicts of Interest: The authors declare no conflict of interest.

\section{References}

1. Bateson, W.; Gregory, R.P. On the inheritance of heterostylism in Primula. Proc. R. Soc. Lond. Ser. B 1905, 76, 581-586. [CrossRef]

2. Barrett, S.C.H.; Cruzan, M.B. Incompatibility in heterostylous plants. In Genetic Control of Self-Incompatibility and Reproductive Development in Flowering Plants; Williams, E.G., Ed.; Kluwer Academic Publishers: Dordrecht, The Netherlands, 1994; pp. 189-219. [CrossRef]

3. Darwin, C. The Different Forms of Flowers on Plants of the Same Species; John Murray: London, UK, 1877. 
4. Mather, K. The genetical architecture of heterostyly in Primula sinensis. Evolution 1950, 4, 340-352. [CrossRef]

5. Lewis, D.; Jones, D.A. The genetics of heterostyly. In Evolution and Function of Heterostyly; Barrett, S.C.H., Ed.; Springer: Berlin, Germany, 1992; pp. 129-150. [CrossRef]

6. Barrett, S.C.H.; Shore, J.S. New insights on heterostyly: Comparative biology, ecology and genetics. In Self-Incompatibility in Flowering Plants-Evolution, Diversity and Mechanisms; Franklin-Tong, V.E., Ed.; Springer: Berlin, Germany, 2008; pp. 3-32.

7. Kappel, C.; Huu, C.N.; Lenhard, M. A short story gets longer: Recent insights into the molecular basis of heterostyly. J. Exp. Bot. 2017, 68, 5719-5730. [CrossRef] [PubMed]

8. Yasui, Y.; Mori, M.; Aii, J.; Abe, T.; Masumoto, D.; Sato, S.; Hayashi, Y.; Ohnishi, O.; Ota, T. S-LOCUS EARLY FLOWERING 3 is exclusively present in the genomes of short-styled buckwheat plants that exhibit heteromorphic self-incompatibility. PLoS ONE 2012, 7, 1-9. [CrossRef] [PubMed]

9. Yasui, Y.; Hirakawa, H.; Ueno, M.; Matsui, K.; Katsube-Tanaka, T.; Yang, S.J.; Aii, J.; Sato, S.; Mori, M. Assembly of the draft genome of buckwheat and its applications in identifying agronomically useful genes. DNA Res. 2016, 23, 215-224. [CrossRef] [PubMed]

10. Li, J.; Cocker, J.M.; Wright, J.; Webster, M.A.; McMullan, M.; Dyer, S.; Swarbreck, D.; Caccamo, M.; Oosterhout, C.V.; Gilmartin, P.M. Genetic architecture and evolution of the $S$ locus supergene in Primula vulgaris. Nat. Plants 2016, 2, 16188. [CrossRef] [PubMed]

11. Shore, J.S.; Hamam, H.J.; Chafe, P.D.J.; Labonne, J.D.J.; Henning, P.M.; McCubbin, A.G. The long and short of the S-locus in Turnera (Passifloraceae). New Phytol. 2019, 224, 1316-1329. [CrossRef]

12. Nowak, M.D.; Russo, G.; Schlapbach, R.; Huu, C.N.; Lenhard, M.; Conti, E. The draft genome of Primula veris yields insights into the molecular basis of heterostyly. Genome Biol. 2015, 16, 12. [CrossRef]

13. Huu, C.N.; Kappel, C.; Keller, B.; Sicard, A.; Takebayashi, Y.; Breuninger, H.; Nowak, M.D.; Bäurle, I.; Himmelbach, A.; Burkart, M.; et al. Presence versus absence of CYP734A50 underlies the style-length dimorphism in primroses. eLife 2016, 5, e17956. [CrossRef]

14. Huu, C.N.; Keller, B.; Conti, E.; Kappel, C.; Lenhard, M. Supergene evolution via stepwise duplications and neofunctionalization of a floral-organ identity gene. Proc. Natl. Acad. Sci. USA 2020, 117, 23149-23157. [CrossRef]

15. Burrows, B.A.; McCubbin, A.G. Sequencing the genomic regions flanking S-linked PvGLO sequences confirm the presence of two GLO loci, one of which lies adjacent to the style-length determinant gene CYP734A50. Plant Reprod. 2017, 30, 53-67. [CrossRef] [PubMed]

16. Neff, M.M.; Nguyen, S.M.; Malancharuvil, E.J.; Fujioka, S.; Noguchi, T.; Seto, H.; Tsubuki, M.; Honda, T.; Takatsuto, S.; Yoshida, S.; et al. Bas1: A gene regulating brassinosteroid levels and light responsiveness in Arabidopsis. Proc. Natl. Acad. Sci. USA 1999, 96, 15316-15323. [CrossRef] [PubMed]

17. Cheng, Y.; Dai, X.; Zhao, Y. Auxin biosynthesis by the YUCCA flavin monooxygenases controls formation of floral organs and vascular tissues in Arabidopsis. Gene Dev. 2006, 20, 1790-1799. [CrossRef] [PubMed]

18. Cecchetti, V.; Altamura, M.M.; Falasca, G.; Costantino, P.; Cardarelli, M. Auxin regulates Arabidopsis anther dehiscence, pollen maturation, and filament elongation. Plant Cell 2008, 20, 1760-1774. [CrossRef]

19. Roh, H.; Jeong, C.W.; Fujioka, S.; Kim, Y.K.; Lee, S.; Ahn, J.H.; Choi, Y.D.; Lee, J.S. Genetic evidence for the reduction of brassinosteroid levels by a BAHD acyltransferase-like protein in Arabidopsis. Plant Physiol. 2012, 159, 696-709. [CrossRef]

20. Henning, P.M.; Shore, J.S.; McCubbin, A.G. Transcriptome and Network Analyses of Heterostyly in Turnera subulata Provide Mechanistic Insights: Are S-Loci a Red-Light for Pistil Elongation? Plants 2020, 9, 713. [CrossRef]

21. D'Auria, J.C. Acyltransferases in plants: A good time to be BAHD. Curr. Opin. Plant Biol. 2006, 9, 331-340. [CrossRef]

22. St-Pierre, B.; Luca, V. The cell and developmental biology of alkaloid biosynthesis. Trends Plant Sci. 2000, 5, 168-173. [CrossRef]

23. Beekwilder, J.; Alvarez-huerta, M.; Neef, E.; Verstappen, F.W.A.; Boumeester, H.J.; Aheroni, A. State of the Field: Functional Characterization of Enzymes Forming Volatile Esters from Strawberry and Banana. Plant Physiol. 2004, 135, 1865-1878. [CrossRef]

24. Okada, T.; Hirai, M.Y.; Suzuki, H.; Yamazaki, M.; Saito, K. Molecular characterization of a novel quinolizidine alkaloid O-tigloyltransferase: cDNA cloning; catalytic activity of recombinant protein and expression analysis in Lupinus plants. Plant Cell Physiol. 2005, 46, 233-244. [CrossRef] 
25. Stewart, C.; Kang, B.C.; Liu, K.; Mazourek, M.; Moore, S.; Young, E.; Yoo, Y.; Kim, B.-D.; Paran, I.; Jahn, M.M. The Pun1 gene for pungency in pepper encodes a putative acyltransferase. Plant J. 2005, 42, 675-688. [CrossRef] [PubMed]

26. Bishop, G.J.; Koncz, C. Brassinosteroids and plant steroid hormone signaling. Plant Cell 2002, 14, 97-111. [CrossRef] [PubMed]

27. Symons, G.M.; Reid, J.B. Brassinosteroids do not undergo long-distance transport in pea. Implications for the regulation of endogenous brassinosteroid levels. Plant Physiol. 2004, 135, 2196-2206. [CrossRef] [PubMed]

28. Choe, S.; Dilkes, B.P.; Fujioka, S.; Takatsuto, S.; Sakurai, A.; Feldmann, K.A. The DWF4 gene of Arabidopsis encodes a Cytochrome P450 that mediates multiple $22 \alpha$-hydroxylation steps in brassinosteroid biosynthesis. Plant Cell 1998, 10, 231-243. [CrossRef]

29. Li, J.; Nagpal, P.; Vitart, V.; McMorris, T.C.; Chory, J. A role for brassinosteroids in light-dependent development of Arabidopsis. Science 1996, 272, 398-401. [CrossRef]

30. Szekeres, M.; Nemeth, K.; Kalman, Z.; Mathur, J.; Kauschmann, A.; Altmann, T.; Redei, G.P.; Nagy, F.; Schell, J.; Koncz, C. Brassinosteroids rescue the deficiency of CYP90, a cytochrome P450, controlling cell elongation and de-etiolation in Arabidopsis. Cell 1996, 85, 171-182. [CrossRef]

31. Zhao, B.; Li, J. Regulation of Brassinosteroid Biosynthesis and Inactivation. J. Int. Plant Biol. 2012, 54, 746-759. [CrossRef]

32. Tanaka, K.; Asami, T.; Yoshida, S.; Nakamura, Y.; Matsuo, T.; Okamoto, S. Brassinosteroid homeostasis in Arabidopsis is ensured by feedback expressions of multiple genes involved in its metabolism. Plant Physiol. 2005, 138, 1117-1125. [CrossRef]

33. Turk, E.M.; Fujioka, S.; Seto, H.; Shimada, Y.; Takatsuto, S.; Yoshida, S.; Denzel, M.A.; Torres, Q.I.; Neff, M.M. CYP72B1 inactivates brassinosteroid hormones: An intersection between photomorphogenesis and plant steroid signal transduction. Plant Physiol. 2003, 133, 1643-1653. [CrossRef]

34. Zhang, Z.; Xu, L. Arabidopsis BRASSINOSTEROID INACTIVATOR2 is a typical BAHD acyltransferase involved in brassinosteroid homeostasis. J. Exp. Bot. 2018, 62, 1925-1941. [CrossRef]

35. Clough, S.J.; Bent, A.F. Floral dip: A simplified method for Agrobacterium-mediated transformation of Arabidopsis thaliana. Plant J. 1998, 16, 735-743. [CrossRef] [PubMed]

36. Koncz, C.; Schell, J. The promoter of TI-DNA gene 5 controls the tissue-specific expression of chimeric genes carried by a novel type of Agrobacterium binary vector. Mol. Genet. Genom. 1986, 204, 383-396. [CrossRef]

37. Choe, S.; Fujioka, S.; Noguchi, T.; Takatsuto, S.; Yoshida, S.; Feldmann, K.A. Overexpression of DWARF4 in the brassinosteroid biosynthetic pathway results in increased vegetative growth and seed yield in Arabidopsis. Plant J. 2001, 26, 573-582. [CrossRef] [PubMed]

38. Song, L.; Zhou, X.Y.; Li, L.; Xue, L.J.; Yang, X.; Xue, H.W. Genome-wide analysis revealed the complex regulatory network of brassinosteroid effects in photomorphogenesis. Mol. Plant 2009, 2, 755-772. [CrossRef] [PubMed]

39. Bancos, S.; Szatmári, A.-M.; Castle, J.; Kozma-Bognár, L.; Shibata, K.; Yokota, T.; Bishop, G.J.; Nagy, F.; Szekeres, M. Diurnal Regulation of the Brassinosteroid-Biosynthetic CPD Gene in Arabidopsis. Plant Physiol. 2006, 141, 299-309. [CrossRef]

40. Chory, J.; Nagpal, P.; Peto, C.A. Phenotypic and genetic analysis of det2, a new mutant that affects light-regulated seedling development in Arabidopsis. Plant Cell 1991, 3, 445-459. [CrossRef]

41. Choi, S.; Cho, Y.H.; Kim, K.; Matsui, M.; Son, S.-H.; Fujioka, S.; Hwang, I. BAT1, a putative acyltransferase, modulates brassinosteroid levels in Arabidopsis. Plant J. 2013, 73, 380-391. [CrossRef]

42. Wang, M.; Liu, X.; Wang, R.; Wanchun, L.; Rodermel, S.; Yu, F. Overexpression of a putative Arabidopsis BAHD acyltransferase causes dwarfism that can be rescued by brassinosteroid. J. Exp. Bot. 2012, 63, 5787-5801. [CrossRef]

43. Livak, K.J.; Schmittgen, T.D. Analysis of relative gene expression data using real-time quantitative PCR and the $2^{-\Delta \Delta C T}$ method. Methods 2001, 25, 402-408. [CrossRef]

44. Jacques, C.N.; Hulbert, A.; Westenskow, S.; Neff, M.M. Production location of the gelling agent, Phytagel, has a significant impact on Arabidopsis thaliana seedling phenotypic analysis. PLoS ONE 2020, 15, e0228515. [CrossRef] 
45. Sandhu, K.S.; Koirala, P.S.; Neff, M.M. The ben1-1 brassinosteroid-catabolism mutation is unstable due to epigenetic modifications of the intronic T-DNA insertion. G3 2013, 4, 1587-1595. [CrossRef] [PubMed]

46. Abràmoff, M.D.; Magalhães, P.J.; Ram, S.J. Image processing with imageJ. Biophotonics Int. 2004, 11, 36-41. [CrossRef]

Publisher's Note: MDPI stays neutral with regard to jurisdictional claims in published maps and institutional affiliations.

(C) 2020 by the authors. Licensee MDPI, Basel, Switzerland. This article is an open access article distributed under the terms and conditions of the Creative Commons Attribution (CC BY) license (http://creativecommons.org/licenses/by/4.0/). 